\title{
EVALUATING DAMAGE ASSESSMENT OF BREACHES ALONG THE EMBANKMENTS OF INDUS RIVER DURING FLOOD 2010 USING REMOTE SENSING TECHNIQUES
}

\author{
R. Ahmad ${ }^{\mathrm{a}, *}$, Daniyal ${ }^{\mathrm{a}}$ \\ a Space Technology Applications Directorate, Space Application Research Wing, SUPARCO HQs, Karachi, Pakistan, \\ iraheelahmad@gmail.com, ddaniyal@yahoo.com
}

KEY WORDS: Breaches, Damage assessment, Floods, Remote Sensing

\begin{abstract}
:
Natural disasters cause human sufferings and property loss, if not managed properly. It cannot be prevented but their adverse impacts can be reduced through proper planning and disaster mitigation measures. The floods triggered by heavy rains during July 2010 in Pakistan caused swallowing of rivers causing human, agriculture, livestock and property losses in almost all over the country. The heavy rains in upper part of country were attributed to El-Nina effect. Accumulated water in the rivers floodplain overtopped and breached flood protective infrastructure. Flood damage particularly in Sindh province was caused by breaches in the embankments and even after months of flood recession in rivers, flood water affected settled areas in the province. This study evaluates the role of satellite remote sensing particularly in assessment of breaches and consequential damages as well as measures leading to minimize the effects of floods caused by breaches in flood protective infrastructure. More than 50 SPOT-5 imageries had been used for this purpose and breached areas were delineated using pre and post flood imageries, later on rehabilitation work were also monitored. A total 136 breaches were delineated out of which 60 were in the Punjab and 76 in Sindh province. The study demonstrates the potentials of satellite remote sensing for mapping and monitoring natural disasters and devising mitigation strategies.
\end{abstract}

\section{INTRODUCTION}

Satellite remote sensing images are the effective means for rapid response in case of emergencies and disasters. It provides real time synoptic and temporal coverage (Berning, 2000), (Boyles, 1998). This holds also true in case of flood mapping, monitoring and damage assessment as well as planning for recovery and rehabilitation. In this way, satellite remote sensing is emerging as a powerful tool in mapping disasters and damage assessment (Hyndman, 2006). Flood mapping and extent of destruction resulted due to breaches can be evaluated by acquiring relatively high resolution data such as SPOT 5 data. Since, the flood event duration is comparatively more than earthquakes; therefore, temporal resolution can be compromised to few days especially in case of damage assessment.

Floods are natural hazards which greatly affect human civilization settled along the river banks and coastal areas (Sharma, 1996). The river floods are mainly result of heavy rainfall, melting of snow or both. In Pakistan during summers, accumulated snow in mountains begins to melt and coincide with monsoon season. Rains coupled with snow melt also caused river flooding in near history. Floods of 1973 and 1976 are categorized as super floods which caused major devastation in the country.

In this study a comprehensive database of the flood protective infrastructure including embankments of the Indus flood plain is developed and studied in detail. Pre and post flood comparative analysis was carried out to ascertain the condition of embankments. This study also delineates the vulnerable areas which need additional measures for the protection of embankments during floods.

\section{PAKISTAN FLOOD 2010}

The unprecedented rains started havoc in Khyber Pakhtunkhwa and Gilgit Baltistan provinces during July 2010. The accumulated water rushed in rivers particularly the Indus river flooding the vast flood plains. The flood water also overtopped and breached the banks and embankments in Punjab and Sindh provinces. In addition, the torrential rains flooded and damaged the surrounding areas in D.G. Khan, D.I. Khan and Kirthar Range. National Disaster Management Authority (NDMA) reported 100,000 sq. $\mathrm{km}$ flooded area throughout the country with 20 million affected people among them 1,984 people lost their lives.

The enormous flood water posed serious threat to minor as well as major dams and head-works. The river flow flushed thousands of settlements through hundreds of breaches in river embankments. This fail down was somehow obvious as the embankments were not designed to sustain that enormous amount of water. Water spilled over flat lands rampantly that immersed a vast area of residential and cultivated land under several feet wide blanket of water. This calamitous event demanded a series of scientific analysis to identify causes of embankment breaches.

The embankments are supposed to be maintained by local government on yearly basis and the funds have also been allocated for this purpose. Although there are multiple embankment lines of defense, yet there is a certain embankment

\footnotetext{
* Corresponding author
} 
limit to desist water from penetrating in settlements. This study covers the identification of breaches through satellite data and evaluation of conditions that caused breaches through water flow analysis and temporal assessment of embankment condition using pre-flood images. The evaluation was carried out using SPOT $4 \& 5$ satellite images with spatial resolution of 2.5 to $20 \mathrm{~m}$.

\section{METHODOLOGY \& RESULTS}

The methodology for delineation of breaches and mapping of embankments rehabilitation work consists of four phases:

3.1 Satellite data and study area selection

3.2 Pre-flood assessment to identify flood vulnerable areas and weak embankments

3.3 Identification of breaches by comparing during and pre flood satellite images

3.4 Validation of embankment repair work by comparing during-flood and post-flood images

\subsection{Satellite Data and Study Area Selection}

The study area comprised of the Indus River flood plain from Jinnah barrage in Punjab to deltaic region in southern Sindh province. The study is further focused on those areas where breaches in protective embankments occurred.

Data selection for delineation of breaches in embankment/canals needs comprehensive analysis and expertise. Few important techniques which need to be critically analyzed for selecting satellite data are highlighted below:

$>$ Satellite images, should not be selected of very next dates after the flood because it is difficult to measure the length of breaches as it keeps on eroding from the sides due to the flash flow of water.

$>$ While delineating the breaches, it is necessary to compare pre-flood and post-flood images in order to ensure that the embankment is not already damaged.

$>$ The high level of flood water may cause difficulty in differentiating between a breach and an over topping. This problem was resolved by comparing the postflood images of later dates after the decrease of water level.

In the light of the above mentioned points, SPOT-5 data of 2.5 meter spatial resolution from August to November, 2010 were selected to evaluate the breached areas in Indus flood plain. The SPOT 5 images of March - April, 2011 were also used to monitor the rehabilitation of breaches.

\subsection{Pre-Floods Study: Identification of Breach Vulnerable Areas}

Vulnerable areas which were susceptible to breaches were mapped using slope, sinks and flow direction maps of the areas. The sink areas (low-lying with respect to neighboring areas) were potentially more prone to floods due to gradient differences. The gradient differences provided the natural routes for flood water to rush through breaches. Fig. 1 shows the Digital Elevation Model (DEM) of Pakistan depicting the general trend of elevations.

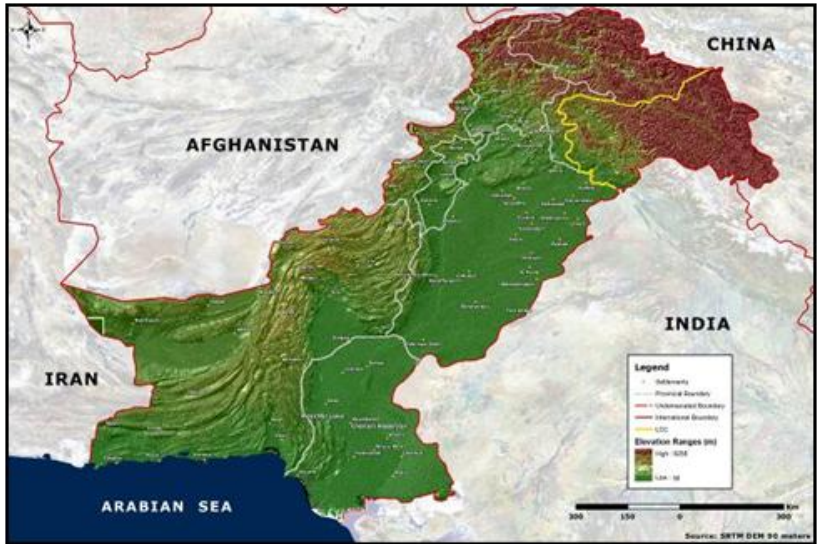

Figure 1. DEM showing elevation perspective of Pakistan

\subsection{During-Flood Study: Delineation of Breaches}

The delineation of breaches was carried out by observing high flow of flood water outside the embankments. Once a breach along the embankment or canal was identified, its length and status during pre and post flood situation was analyzed. The comparative analysis with a pre flood image gave the information about the condition of embankment before the flood.

The assessment revealed that total 136 breaches were demarcated in which 60 were delineated in Punjab and 76 were delineated in the Sindh province. Most of the small breaches happened as a consequence of three main breaches i.e. Left Marginal Bund (LMB) in Punjab, Tori and Kot Almo in upper and lower Sindh.

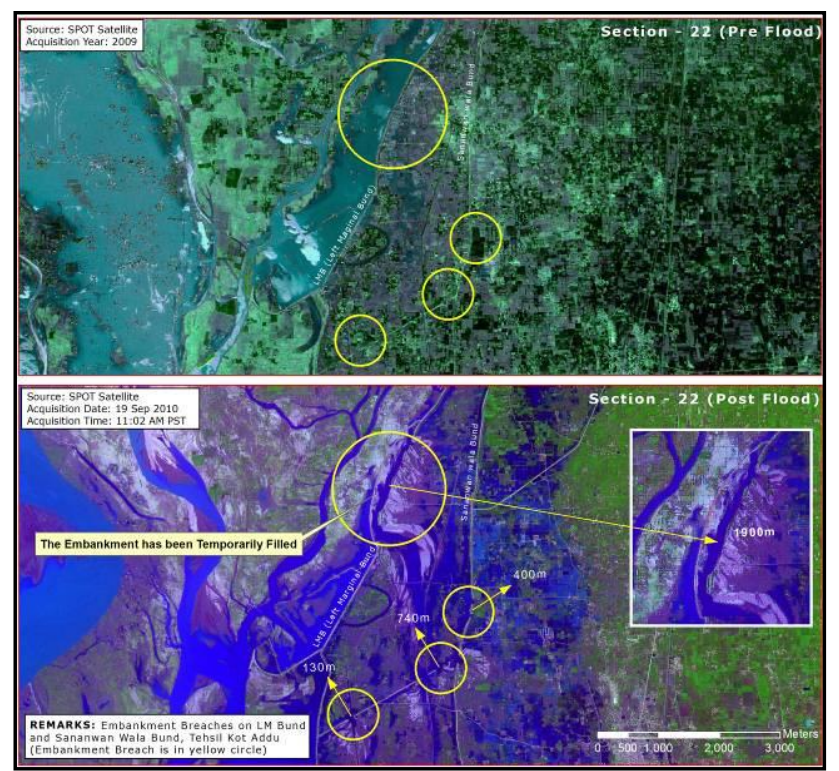

Figure 2. LMB Breach near Taunsa Barrage, Punjab

Fig. 2 shows the breach in LMB at Taunsa barrage which bursted and caused a 1900 meter long breach. This breach damaged Layyah, Bhakkar, and Muzaffargarh Districts. Several breaches formed as a consequence of LMB breach in adjacent bunds and canals particularly left bank canals (Muzaffargarh canal, Taunsa-Punjnad link canal) of Taunsa barrage.

In Sindh, the major breach which almost diverted the flow of Indus river was Tori breach in downstream of Guddu barrage. Fig. 3 shows the Tori breach on Indus river which caused multiple breaches in canals and roads. Tori breach resulted in 


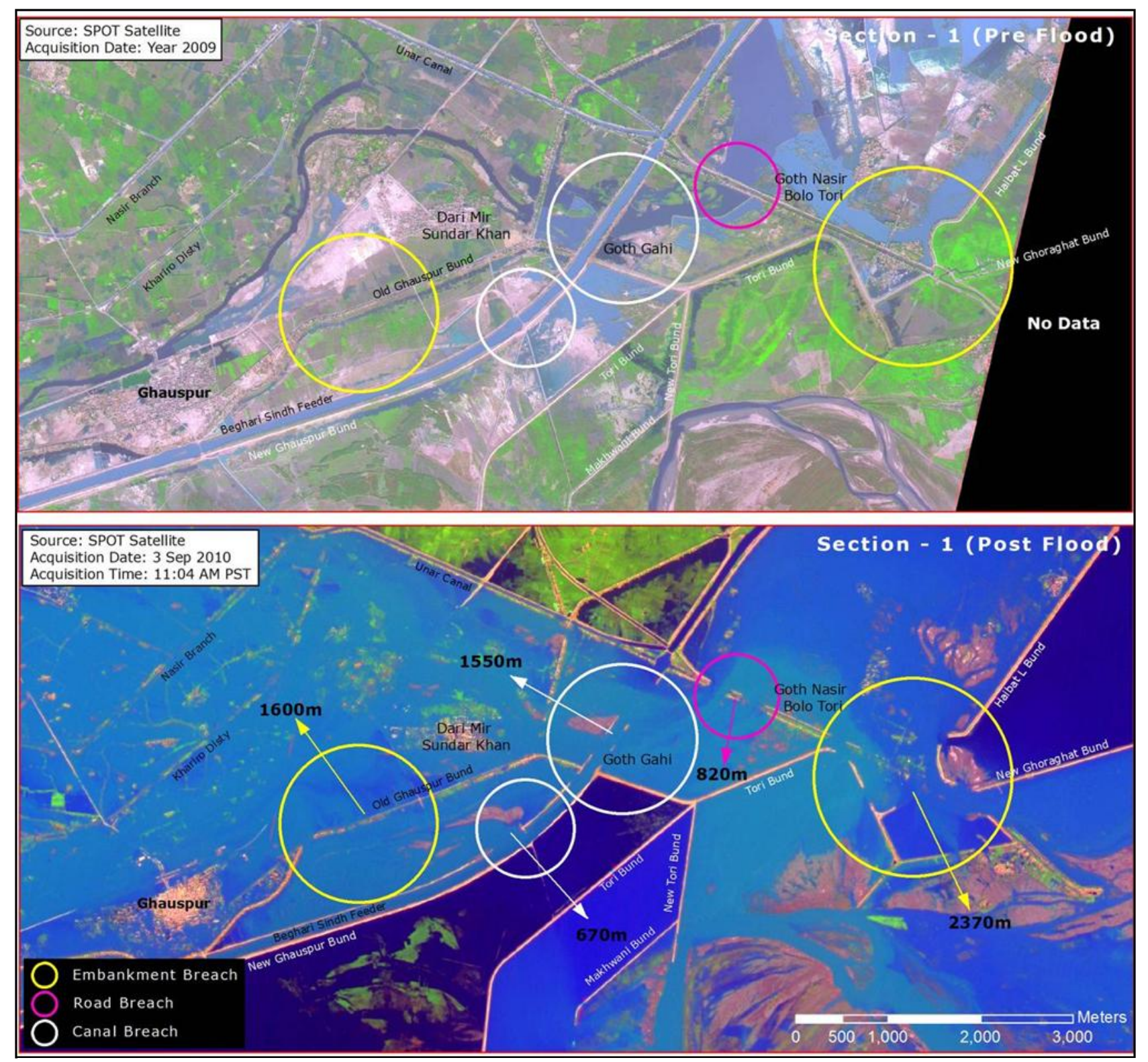

Figure 3. Tori Breach in Sindh

vast destruction in the province particularly in Kashmore, Jacobabad, Qambar Shahdadkot and Dadu districts. The water flow on the right bank of Indus river was obvious because of the natural depressions in the north western part of Sindh.

Few breaches were not destructive due to presence of second defense line of embankments. Destruction of infrastructure created major hurdle in evacuation and rehabilitation especially due to damaged roads. Fig. 4 shows a 60 meter breach which occurred on Dadu-Moro road embankment on Indus river (linking National Highway N-5 to Indus Highway N-55) produced a major infrastructure loss as it disconnected the residents of left and right bank of Indus river in the area.

\subsection{Post-Flood Study: Validating the Breaches Rehabilitation Status}

After delineating the breaches, the fourth phase of the study involved the monitoring of breach rehabilitation and restoration work. The phase needed to have a comparative analysis of during-flood images with the post-flood images. The monitoring revealed that by the month of April 2011, some of
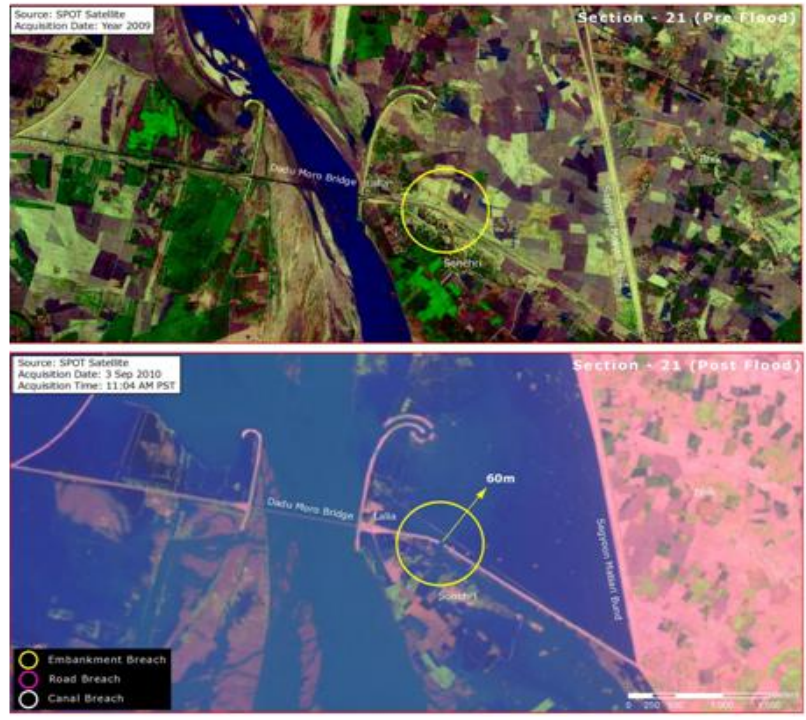

Figure 4. . Dadu-Moro Road Breach, Sindh 
the embankment breaches remained untreated while many of the embankments and canal breaches were temporarily filled and were not completely restored.

The Tori breach in Sindh and LMB in Punjab were filled on urgent basis since these breaches caused major destruction over large areas. Fig. 5 shows the rehabilitation of Tori embankment breach.

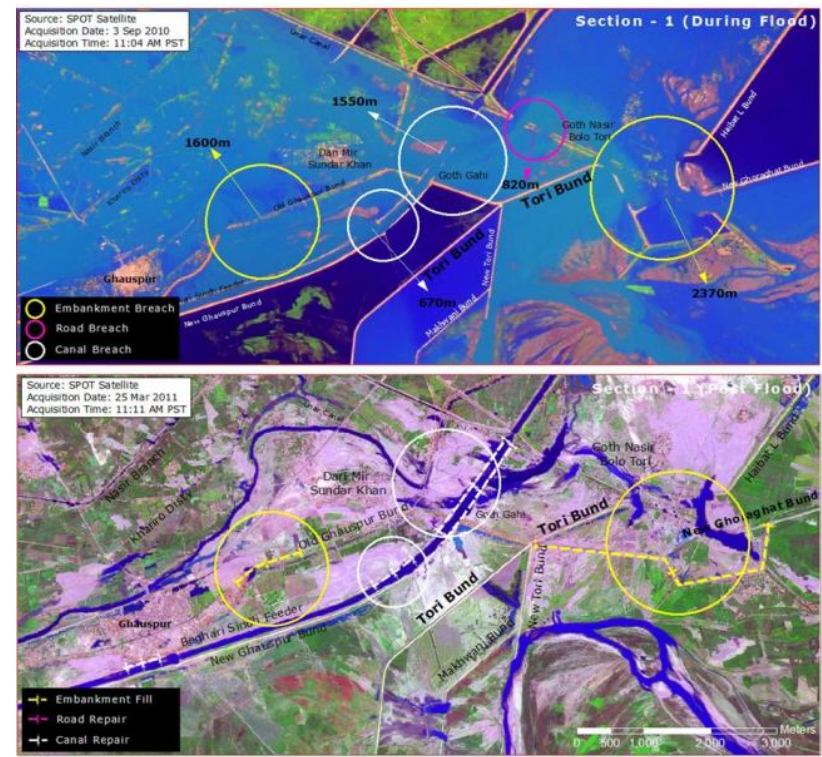

Figure 5. Rehabilitation of Tori Breach, Sindh A new parallel embankment was constructed instead of filling the breach at Tori. Other consequent breaches of Tori (Old Ghauspur and the embankments of Beghari Sindh Feeder) were also rehabilitated as shown in Fig. 5. Ghauspur town was badly affected and water overtopped the Indus highway which passed through the town.
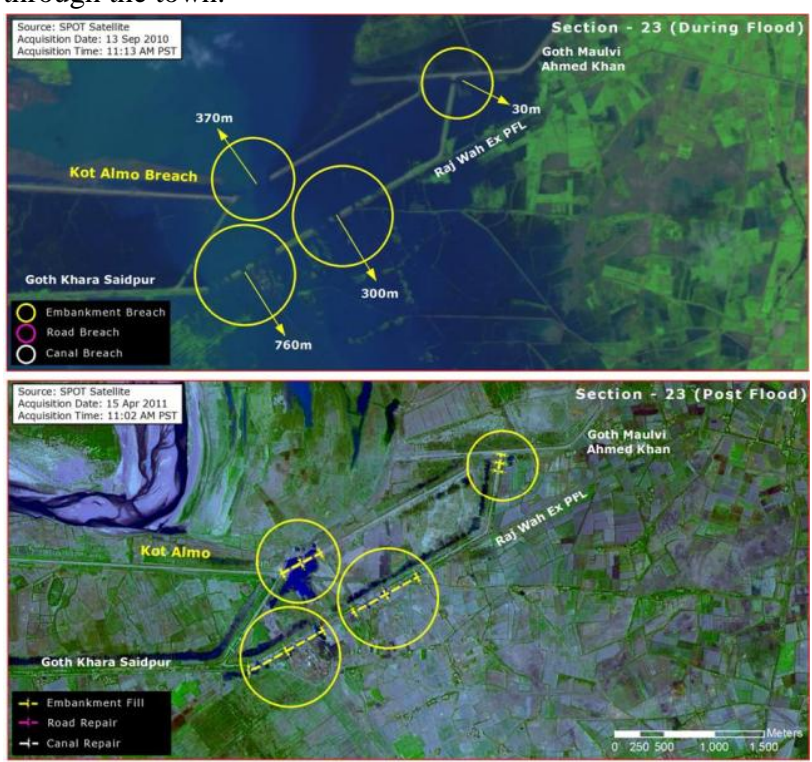

Figure 6. Kot Almo breach, District Thatta, Sindh

Kot Almo embankment breach in district Thatta also destroyed a large area of agricultural belt in lower Sindh. An important city of Sujawal was seriously affected by flood water which rushed from the Kot Almo embankment. These breaches were filled on priority basis as shown in Fig. 6. It is to be noted here that two defense lines of protective embankments were present in the same area. However the water exerted immense pressure on the embankments so that both the defense lines broke and water rushed through. Later on both the embankments were rehabilitated.

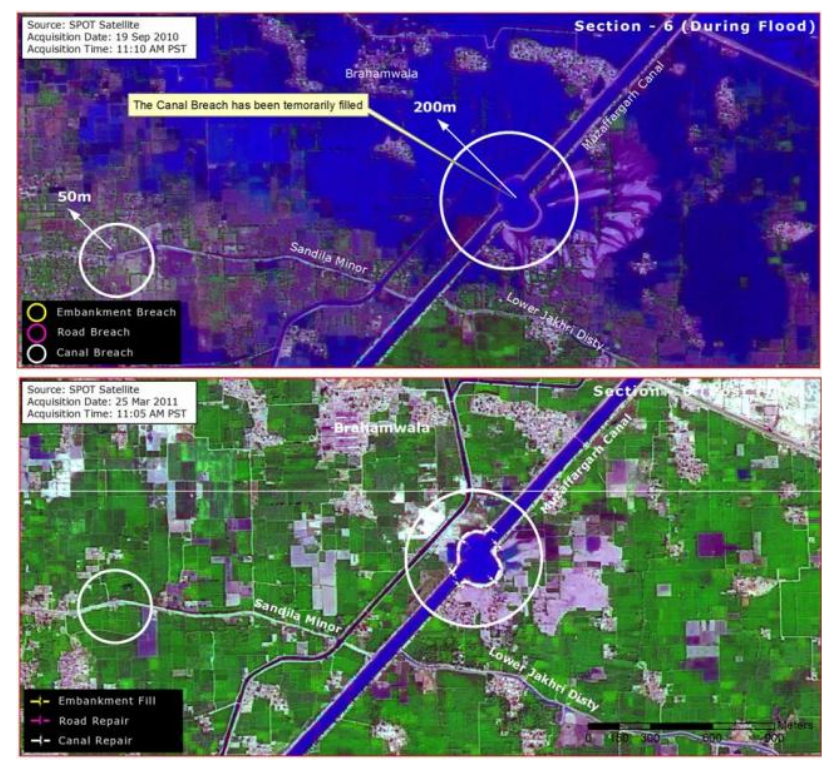

Figure 7. Filling of Muzaffargarh Canal Breach, Punjab

Some of the breaches which were repaired on priority basis were not rehabilitated up to standards such that the width of protective embankments had not been maintained whereas some of the breaches were temporarily filled by creating a curved structure. Such filling have been considered as partially repaired breaches. Fig. 7 shows partial filling of Muzaffargarh canal breach, district Muzaffargarh in Punjab.

\section{CONCLUSION}

The Floods in 2010 can be considered as a benchmark for preparedness programs to avoid the future calamities and for reducing the loss of lives, property and infrastructure. The work demonstrates the potentials of satellite remote sensing for mapping and monitoring of natural disaster and its role in devising mitigation strategies. It is imperative that the potential of such modern technologies must be fully exploited by all stakeholders to find solutions for minimizing the effects of such disasters.

\section{Acknowledgements}

The authors would like to thank their colleagues in SUPARCO (Pakistan Space \& Upper Atmosphere Research Commission) especially Mr. Jawed Ali Qureshi DDG (STA), Mr. Sanaullah Shah, Mr. Zahir Ali, Mr. Ateeq Qureshi, Mr. Shahid Parvez, Mr. Shabbir Raza and Mr. Zeeshan Ahmed for the remarkable contribution to make this research possible.

\section{References}

Berning, C., Viljoen, M.F., and DuPlessis, L.A., "Loss Function for Sugar-cane: Depth and Duration of Inundation as Determinates of Extent of Flood Damage," Water SA, Vol. 26, No. 4, pp. 527-530 (2000)

Berning, C., DuPlessis, L.A., and Viljoen, M.F., "Loss Function for Structural Flood Mitigation Measures," Water SA, Vol. 27, No. 1, pp. 35-38 (2001) 
Boyle, S.J., Tsanis, I.K., and Kanaroglou, P.S., "Developing Geographic Information Systems for Land Use Impact Assessment in Flooding Conditions," J. Water Res. Pl., Vol. 124, No. 2, pp. 89-98 (1998)

Brivo, P.A., Colombo, R., Maggi, M., and Tomasoni, R., "Integration of Remote Sensing Data and GIS for Accurate Mapping of Flooded Areas," Int. J. Remote Sens., Vol. 23, No. 3, pp. 429-441 (2002)

Hyndman, D., and Hyndman, D., "Natural Hazards and Disasters", Thomson Brooks/Cole, (2006)

Stefan Voigt, Thomas Kemper, Torsten Riedlinger, Ralph Kiefl, Klaas Scholte, and HaraldMehl, "Satellite Image Analysis for Disaster and Crisis-Management Support" IEEE Transactions On Geoscience And Remote Sensing, Vol. 45, No. 6, (June 2007)

Sharma, P.K., R. Chopra, V.K. Verma, and A. Thomas, "Flood Management using Remote Sensing technology: The Punjab experience. Int.J. Remote Sensing. 17(17):3511-3521(1996)

National Disaster Management Authority (NDMA), Pakistan, http://www.ndma.gov.pk 